\title{
Sinopse taxonômica da família Combretaceae R. Brown na Região Sul do Brasil
}

\author{
Leonardo von Linsingen ${ }^{1,3}$, Armando Carlos Cervi² e Olavo Guimarães ${ }^{2}$
}

Recebido em 10/11/2008. Aceito em 10/11/2008

RESUMO - (Sinopse taxonômica da família Combretaceae R. Brown na Região Sul do Brasil). O presente trabalho consiste no estudo taxonômico das espécies da família Combretaceae no sul do Brasil. Constatou-se a ocorrência de nove espécies distribuídas em cinco gêneros: Buchenavia kleinii Exell, Combretum fruticosum (Loefl.) Stuntz, Combretum laxum Jacq., Conocarpus erectus L., Laguncularia racemosa (L.) Gaertn. f., Terminalia argentea Mart., Terminalia australis Cambess., Terminalia glabrescens Mart. e Terminalia triflora (Griseb.) Lillo. Terminalia reitzii Exell e Terminalia ulena Engl. ex Alwan \& Stace foram consideradas espécies duvidosas e Conocarpus erectus L. é referida pela primeira vez para o estado do Paraná. Para reconhecimento das espécies são apresentadas chaves de identificação, descrições, ilustrações, distribuição geográfica e comentários.

Palavras-chave: Combretaceae, sul do Brasil, taxonomia

ABSTRACT - (Taxonomic synopsis of the family Combretaceae R. Brown in southern Brazil). This work is a study of the family Combretaceae in southern Brazil. A total of nine species and five genera were recorded: Buchenavia kleinii Exell, Combretum fruticosum (Loefl.) Stuntz, Combretum laxum Jacq., Conocarpus erectus L., Laguncularia racemosa (L.) Gaertn. f., Terminalia argentea Mart., Terminalia australis Cambess., Terminalia glabrescens Mart. and Terminalia triflora (Griseb.) Lillo. Terminalia reitzii Exell and Terminalia uleana Engl. ex Alwan \& Stace were considered doubtful species and Conocarpus erectus L. is reported for the first time in Paraná state. Identification keys, descriptions, ilustrations, geographic distribution and comments on the species are presented.

Key words: Combretaceae, southern Brazil, taxonomy

\section{Introdução}

A família Combretaceae compreende cerca de 475 espécies e 20 gêneros, com distribuição pantropical e a maioria das espécies ocorrem na África. A característica mais marcante do grupo é a presença de tricomas compartimentados. No Brasil, ocorrem seis gêneros com aproximadamente 70 espécies que são encontradas em quase todas as formações vegetacionais brasileiras (Marquete \& Valente 1997).

De acordo com Exell \& Stace (1966), Combretaceae subdivide-se em duas subfamílias: Strephonematoideae, sem representantes na flora brasileira, com ovário semiínfero, e Combretoideae, com ovário ínfero, dividida em duas tribos Laguncularieae e Combreteae as quais apresentam inúmeros representantes na flora neotropical.

Os trabalhos clássicos sobre a taxonomia das Combretaceae foram elaborados por Brown (1810), Eichler (1869), Engler \& Diels (1899), Exell (1931), Exell \& Stace (1966). Dentre os estudos realizados no Brasil, destacam-se os de Exell \& Reitz (1967), Loiola \& Sales (1996), Marquete (1984; 1995), Marquete \& Valente (1996; 2003) e Marquete et al. (2003).

Este trabalho tem como objetivo o estudo taxonômico das Combretaceae da Região Sul do Brasil (Paraná, Santa Catarina e Rio Grande do Sul), procurando fornecer dados que contribuam para o entendimento dos gêneros e espécies, além de atualizar suas distribuições geográficas e evidenciar características morfológicas importantes para o reconhecimento das espécies.

\section{Material e métodos}

Os dados obtidos resultam de revisão bibliográfica e análise das coleções disponíveis nos herbários: ETESN, FUEL, HAS, HBR, HPEL, ICN, MBM, PACA, SMDB, SP, SPF e UPCP cujas siglas seguem Holmgren et al. (1990). Expedições científicas foram realizadas em todas as formações fitogeográficas do Sul do Brasil, durante os anos de 2005 e 2006. Material botânico foi coletado e registrado os dados ecológicos sobre as plantas. Amostras foliares, florais e frutíferas foram fixadas em álcool a $70 \%$ e utilizadas na análise morfológica.

O material foi herborizado segundo técnicas usuais e incorporado ao acervo do herbário UPCB. A terminologia utilizada nas tipologias vegetacionais baseou-se em Veloso (1992), e as características morfológicas e anatômicas em Lawrence et al. (1951), Radford et al. (1974) e Stace (1965).

A identificação dos espécimes foi realizada por meio de literatura, comparação com descrições e material de herbário. A classificação adotada para a família foi a de Exell \& Stace (1966) e para o nome dos autores das espécies, baseou-se em Brummitt \& Powell (1992).

Para designação das espécies ameaçadas de extinção foi seguido o proposto pela União Internacional para Conservação da Natureza (IUCN 2003) e através de informações compiladas ao longo do estudo.

\section{Resultados e discussão}

Combretaceae R. Brown, Prodr. Fl. Nov. Holl.: 351. 1810.

Árvores ou arbustos escandentes. Folhas opostas ou alternas, simples, inteiras, sem estípulas, cobertas por tricomas compartimentados, escamosos ou glandulares; domácias muitas vezes presentes. Inflorescências espigas, panículas de espigas, racemos ou panículas terminais ou axilares, menos comum capitada; brácteas muitas vezes presentes. Flores actinomorfas ou zigomorfas, menos freqüentes diócas, tetrâmeras ou pentâmeras, receptáculo dividido em duas partes, a inferior envolvendo o ovário; a superior em tubo curto ou comprido terminando nos lobos

\footnotetext{
1 Parte da Dissertação de Mestrado do primeiro Autor

2 Universidade Federal do Paraná, Departamento de Botânica, Centro Politécnico, Curitiba, PR, Brasil

3 Autor para correspondência: cerradopr@yahoo.com.br
} 
do cálice; lobos do cálice 4 ou 5 , de modo geral pouco desenvolvidos; pétalas 4, 5 ou ausentes, pequenas ou conspícuas, inseridas entre os lobos do cálice; estames diplostêmones, 8 ou 10, inseridos em 2 verticilos, exsertos, filiformes, subulados ou truncados; anteras versáteis ou adnatas aos filetes, rimosas; disco nectarífero desenvolvido ou inconspícuo na base da parede do receptáculo superior, margem glabra ou pilosa, 5-10 lóbulos; ovário ínfero, unilocular, 2-6 rudimentos seminais pêndulos e ovóides; geralmente exserto. Frutos indeiscentes, betulídios ou drupáceos, 2 a 5 alas, menos freqüente alas inconspícuas ou vestigiais, endocarpo lígneo ou esponjoso; semente 1, sem endosperma, cotilédones convolutos ou plicados.

\section{Chave de identificação para espécies de Combretaceae da região sul do Brasil}

1. Receptáculo inferior com 2 bractéolas adnatas na parte superior 1. Laguncularia racemosa

1. Receptáculo inferior sem bractéolas adnatas

2. Flores com 4 pétalas

3. Flores com pétalas lanceoladas, sublanceoladas ou elípticas, filetes 8-34 mm compr. ...... 2. Combretum fruticosum

3. Flores com pétalas ungüiculadas, filetes 1,8-5,3 mm compr. 3. Combretum laxum

2. Flores apétalas

4. Inflorescências em capítulos globosos

4. Conocarpus erectus

4. Inflorescências em espigas

5. Receptáculo com lobos do cálice inconspícuos, 0,3-0,6 mm compr., anteras adnatas aos filetes

5. Receptáculo com lobos do cálice conspícuos, 1-4 mm compr., anteras versáteis aos filetes

6. Frutos com todas as alas menores que a largura do corpo

6. Terminalia australis

6. Frutos com duas alas maiores que a largura do corpo

7. Frutos com 5 alas, escariosas, desiguais

7. Terminalia glabrescens

7. Frutos com 2 alas, coriáceas, iguais

8. Folhas argênteo-tomentosas, principalmente quando jovens, frutos com 2 alas elípticas, transversalmente arredondadas, $2 \times 3-5 \mathrm{~cm}$ compr.

8. Terminalia argentea

8. Folhas rufo-pubescentes, principalmente quando jovens, frutos com 2 alas arredondadas, transversalmente triangulares, subtriangulares, oblongas, $0,8-2,5 \times$ $1,6-4,5 \mathrm{~cm}$ compr.

9. Terminalia triflora

1. Laguncularia racemosa (L.) Gaertn.f. in Fruct. 3, 2:209, pl. 217. 1807.

Conocarpus racemosus L., Syst. Nat. ed. 10, 2: 930. 1759. Fig. 1-10

Árvores 2-5m alt. Ramos glabros, levemente carnosos. Folhas opostas elípticas ou obovadas, 3-4×6-9 cm, coriáceas, base obtusa, ápice mucronado, glândulas de sal acompanhando a extremidade da folha, hidatódios nas regiões abaxiais, glabras em ambas as faces; pecíolos 0,7-1,3 mm, duas glândulas evidentes. Inflorescências panículas de espigas terminais; raque desenvolvida, glabra, $6-10 \mathrm{~cm}$. Flores alvoesverdeadas, 3-4,5 mm, simétricas, pentâmeras; receptáculo glabro, subovado, 3-3,5 mm compr.; bractéolas 2, obovadas, adnatas na parte superior, subopostas, pilosas, 1,8-2×1,5-1,8 mm; prolongamento do receptáculo urceolado, 0,5-0,7 mm; lobos do cálice 5, triangulares, sedosos, margem ciliada, $1 \times 1 \mathrm{~mm}$; disco nectarífero pubérulo, lateralmente inconspícuo; pétalas 5, suborbiculares, glabras, internamente levemente pilosas, ciliadas marginalmente, caducas, $1-1,2 \times$ 1-1,2 mm; estames 10, inclusos, 1-1,5 mm, filetes filiformes, anteras obovadas ou subovadas, $0,4 \times 0,5 \mathrm{~mm}$; ovário cilíndrico, estilete cilíndrico, incluso, 0,6-1,3 mm, estigma filiforme, região terminal capitada. Frutos obovados, estriados, sedosos, 10-15×4-9 mm, lobos do cálice persistentes; pedicelo frutífero inconspícuo, glabro.
Esta espécie apresenta como característica marcante a presença de bractéolas adnatas na região superior do receptáculo inferior. Espécie halófita, sob a influência direta ou indireta do fluxo das marés e por vezes formam agrupamentos típicos nos Manguezais ao longo da costa brasileira, não se encontra ameaçada de extinção. Pode se desenvolver, porém, de maneira menos freqüente, nas restingas. Apresenta padrões disformes de floração e frutificação, variando ao longo do ano. No litoral sul possui maior tendência de floração e frutificação entre os meses de setembro e março.

Distribuição geográfica. No continente Africano ocorre no litoral do Senegal até Angola. Nas Américas do litoral da Flórida central até o sul do Brasil. No Brasil ocorre em toda a costa litorânea, se estendendo até Laguna litoral sul catarinense, limite meridional das formações de manguezais (Tomlinson 1986).

Material examinado: BRASIL. Paraná: Matinhos, 12/XI/2005, von Linsingen \& C. Kaweski 1221 (UPCB); Guaraqueçaba, 10/IV/1995, S.R. Ziller \& W. Maschio 793 (MBM); Guaratuba, 14/VIII/1991, Shirata 1114 (UPCB); Paranaguá, Rio Itibere, G. Hatschbach 870 (PACA; HPEL). Santa Catarina: Araquari, 9/III/2001, O.S. Ribas, Sevegnan \& J.M. Silva 3413 (MBM); Itapoá, Praia do Cabeça, 27/II/1999, A.C. Cervi 6623 (UPCB); Porto Belo, Bombas, 20/II/1989, 
J.A Jarenkow 1227 (HPEL); Laguna, 28/II/1952, R. Reitz \& R.M. Klein 191 (HBR); Palhoça, 22/12/1951, R. Reitz 6150 (PACA); São Francisco do Sul, 9/I/1951, R. Reitz 3796 (HBR).

2. Combretum fruticosum (Loefl.) Stuntz, U.S. Dep. Agr. Bur. Pl. Ind. Seeds et Pl. Import. 31: 86. 1914.

Gaura fruticosa Loefl., Iter Hispanicum 248. 1758.

Fig. 11-15
Árvores ou arbustos escandentes 2-8 m alt. Ramos terminais cilíndricos ou quadrangulares, sinuosos, tricomas escamosos. Folhas opostas, 5-12,5×2-5,5 cm, elípticas, subelípticas, oblongo-lanceoladas, obovadas; base obtusa, cuneada; ápice acuminado, obtuso, menos freqüente rotundo, escamoso em ambas as faces ou mais densamente na abaxial, escamas douradas; nervura principal glabra ou pilosa, as secundárias com tricomas esparsos ou glabros


Figuras 1-10. Laguncularia racemosa (L.) Gaertn f. 1. Ramo com flor. 2. Folha. 3. Inflorescência. 4. Botão floral evidenciando bractéola e bráctea. 5. Flor inteira. 6. Bráctea. 7. Secção longitudinal na flor. 8. Anteras. 9. Fruto jovem. 10. Fruto com 2 bractéolas persistentes (von Linsingen \& Kaweski 1221). 
na abaxial, margens revolutas, domácias ausentes; pecíolos 0,4-1,3 cm, plano-convexos, escamosos. Inflorescências espigas, racemos ou panículas, axilares ou terminais, raque lepidota 3,2-17 cm. Flores esverdeadas, vermelhas, amareloesverdeadas, alaranjadas, simétricas, tetrâmeras, 1,5-3,6 cm; tricomas no ápice, 2-5×0,2-0,4 mm; prolongamento do receptáculo tetrágono, densamente escamoso, raro pubescente, 5,5-11×0,6-1,6 mm; receptáculo campanulado, externamente escamoso ou com tricomas esparsos, internamente viloso, 5-8,5×2-5 mm; lobos do cálice 4 , triangulares, externamente escamosos, internamente pilosos 0,7-2×1-1,8 $\mathrm{mm}$; disco nectarífero desenvolvido, infundibuliforme na base do receptáculo superior, 1,2-4 mm, margem livre, vilosa; pétalas 4 , hialinas, brancas, do mesmo tamanho dos lobos do cálice ou sutilmente maior, lanceoladas, sublanceoladas, elípticas, ápice ensiforme ou agudo, glabras, muitas vezes ciliadas no ápice, trinervadas, 1-2,8×0,3-1,7 mm; estames 10 , filetes filiformes, $8-34 \mathrm{~mm}$ compr.; anteras oblongas, 0,5-1,2×0,2-0,8 mm; ovário cilíndrico, estilete reto, filiforme, $13-39 \mathrm{~mm}$, estigma ligeiramente truncado. Fruto elíptico, ovalado, escamoso, ápice muitas vezes apiculado, quando imaturo rúbido, quando maduro castanho, corpo do fruto 16-23×3,2-6,3 mm; alas 4 , lignificadas, $18-24 \times 5-11 \mathrm{~mm}$. Pedicelo frutífero escamoso, 1,2-4,4 mm.

Pode ser reconhecida facilmente pelo disco nectarífero, desenvolvido, infundibuliforme na base do receptáculo e pela presença de tricomas ferrugíneos, características que a diferenciam de Combretum lanceolatum Pohl ex Eichler, espécie mais próxima. Ocorre em quase todas as formações fitogeográficas do sul do Brasil, não sendo observada na região do Espinilho, área de influência Chaqueana, no Rio Grande do Sul. Muito freqüente na região oeste dos estados do Sul, em áreas de sucessão primária e nas orlas das florestas. Espécie heliófita, escandente sobre as espécies do dossel da floresta. Combretum fruticosum encontra-se protegido da extinção por se desenvolver no Parque Nacional do Iguaçu e nas Áreas de Preservação Ambiental de Guaraqueçaba e Guaratuba, ambos no estado do Paraná. Floresce e frutifica de setembro a janeiro.

Distribuição geográfica: México, América Central e do Sul. Brasil: Piauí, Pernambuco, Bahia, Goiás, Distrito Federal, Mato Grosso, Mato Grosso do Sul, Minas Gerais, Espírito Santo, Rio de Janeiro, São Paulo, Paraná, Santa Catarina e Rio Grande do Sul (Marquete 1995).

Material examinado: BRASIL. Paraná: Cerro Azul, 5/I/1990, J.M. Silva \& J. Cordeiro 786 (MBM); Guarapuava, Lagoa Seca, 14/I/1983, J.R. Pirani, O.Yano, D.P. Santos 427 (SP); Guaraqueçaba, Liso, 3/I/1964, R. Reitz \& R.M. Klein 16895 (HBR); Guaratuba, Rasgadinho, VII/1996, A.C. Svalenski \& C.V. Roderjan 141 (MBM); Ibipora, 11/II/1996, M.C. Dias 234 (UPCB); Laranjeiras do Sul, 11/XII/1996, von Linsingen \& C. Kaveski 1233 (UPCB); Londrina, Faxinal São Sebastião, 29/I/1937, G. Tesmam s.n. (MBM); Rio Branco do Sul, Itupava, 26/XII/1978, G. Hatschbach 41858 (UPCB; SPF). Santa Catarina: Catanduvas, 28/XII/1963, R. Reitz \&
R.M. Klein 16385 (MBM, HBR); Curitibanos, 12/III/1984, G. Hashimoto 865 (MBM); Erexim, 2/I/1966, T.I. Paviani s.n. (SMDB); Piratuba, 29/I/1987, J.A. Jarenkow 824 (PACA). Rio Grande do Sul: Caxias do Sul, 27/I/1999, A. Kegler 156 (MBM); Gravataí, 18/I/1949, S.J. Rambo s.n. (PACA); Porto Alegre, 2///1933, S.J. Rambo s.n. (PACA, SMDB); São Miguel, 12/III/1969, J. Favalli, A. Ferreira \& B. Irgang s.n. (ICN).

\section{Combretum laxum Jacq., Enum. Pl. Carib.:19. 1760.}

Fig. 16-20

Árvores ou arbustos escandentes, 2-17 m alt. Ramos pubescentes, ferrugíneos. Folhas opostas ovadolanceoladas, oblongas, ápice acuminado ou longamente acuminado, base obtusa, glabra ou escamas esparsas na face superior, tricomas compartimentalizados esparsos na nervura primária na face inferior; domácias marsupiformes, com tricomas na abertura, na axila das nervuras primárias com as secundárias; pecíolos 3-8 mm, pubescentes ou glabros. Inflorescências panícula de espigas terminais ou axilares, $25-120 \mathrm{~mm}$; raques pubescentes, ferrugíneas. Flores alvas, brancas a suavemente amareladas, 4-6 mm compr.; pubescentes, ferrugíneas, 0,8-1,2 $\mathrm{mm}$; prolongamento do receptáculo levemente tetrágono, densamente escamoso, moderada pubescência ferrugínea, 0,5-1,6×0,5-0,9 mm; receptáculo externamente escamoso, tricomas esparsos, internamente piloso ferrugíneo, turbiniforme ou cupuliforme, 1-1,9×0,9-1,7 mm; lobos do cálice 4, curtos, deltóides, 0,2-0,6 $60,5-0,8 \mathrm{~mm}$; disco nectarífero curto na parte superior, glabro, 0,4-1 $\mathrm{mm}$ compr; pétalas 4 , alvas, ungüiculadas, emarginadas ou não no ápice, glabras, 0,7-2×1-2 mm; estames 10 , filetes filiformes, $1,8-5,3 \mathrm{~mm}$ compr., anteras orbiculares, $0,3 \times 0,5 \mathrm{~mm}$; ovário cilíndrico, estilete arqueado na extremidade, 2-5,8 mm compr.; estigma obtuso. Fruto castanho-claro, lanceolado a elíptico, levemente emarginado no ápice, levemente mucronado, $17-24 \times 2-7 \mathrm{~mm}$; alas $14-21 \times$ 3-4 mm; pedicelo frutífero escamoso, $12-26 \mathrm{~mm}$.

Espécie polimorfa, com ampla variação no formato das folhas e na pubescência. Pode ser reconhecida pelos lobos do cálice reduzidos, pétala ungüiculada e pelos frutos elípticos com alas curtas. Pode ser encontrada no noroeste do estado do Paraná, em meio à floresta estacional semidecídua de galeria do rio Paraná, Paranapanema e tributários. Pode-se dizer que Combretum laxum está protegido da extinção por possuir populações estáveis no Parque Nacional da Ilha Grande. Floresce e frutifica de setembro a março.

Distribuição geográfica: desenvolve-se desde a região sul do México até a Argentina. Brasil: Amazonas, Acre, Pará, Ceará, Maranhão, Piauí, Pernambuco, Paraíba, Bahia, Mato Grosso, Mato Grosso do Sul, Goiás, Distrito Federal, Minas Gerais, Espírito Santo, Rio de Janeiro, São Paulo e Paraná (Marquete 1995).

Material examinado: BRASIL. Paraná: Diamante do Norte, 25/I/1990, J.M. Silva \& L.M. Abe 2495 (SPF; HPEL); Guaíra, 18/III/1982, F.S. Muniz 389 (SP); Parque Nacional de Sete Quedas, 17/III/1982, M. Kirizawa 699 (SP, MBM); Icaraíma, 
Paredão das Araras, 28/08/1967, G. Hatschbach 17038 (MBM); Porto Rico, 12/IX/1979, G. Hatschbach 22177 (MBM); Querência do Norte, Rio Ivaí, G. Hatschbach 28867 (MBM); Vila Alta, 25/I/2003, Rio Paraná, C. Kozera 1842 (MBM).
4. Conocarpus erectus L., Sp. Pl. 1: 176-177. 1753.

Fig. 21-30

Árvores 2-5 m alt. Ramos glabros, irregulares, angulosos no ápice. Folhas alternas, lanceoladas, base cuneada, ápice agudo, levemente suculentas, glabras, subglabras na base,

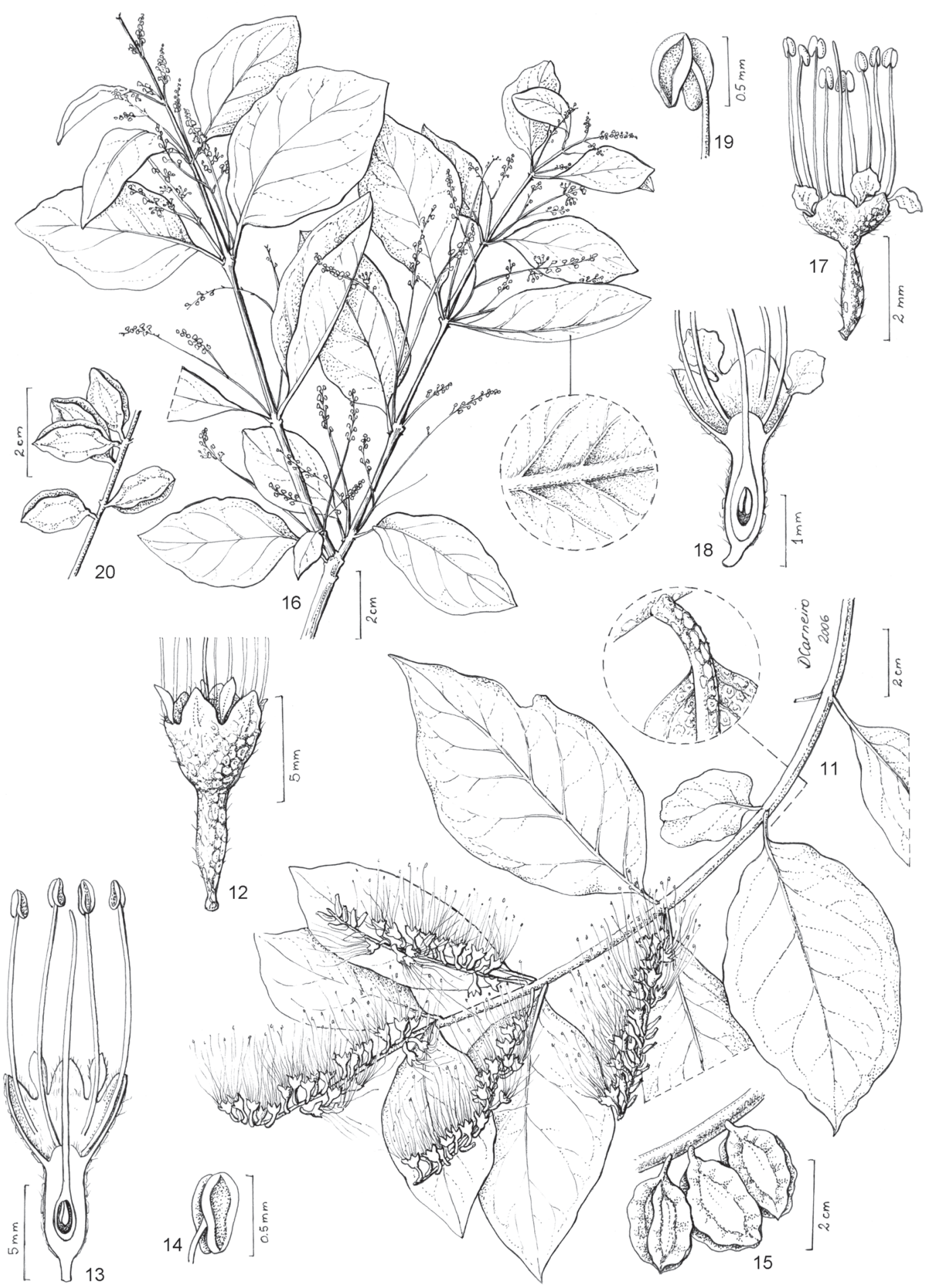

Figuras 11-20. Combretum fruticosum (Loefl.) Stuntz., 11 Ramo com flor. 12. Flor. 13 Secção longitudinal na flor. 14. Antera. 15. Frutos. Combretum laxum Jacq. 16. Ramo com flor. 17. Flor. 18. Secção longitudinal na flor. 19. Antera. 20. Frutos (11-15. von Linsingen \& Kaweski 1233; 16-20. J.M.Silva \& L.M. Abe 2495). 
biglandulosa na base do limbo; domácias lentibuliformes nas axilas da nervura primária com a secundárias na base da face inferior, $3-7 \times 2-3 \mathrm{~cm}$, pecíolos curtos, pubérulos ou glabros, 1-2 mm. Inflorescências capítulos globosos, pedunculados, axilares ou terminais; raque pubescente, 2-6 mm compr. Flores esbranquiçadas a cremes, inconspícuas, 2-2,7 mm; brácteas lanceoladas, tomentosas, caducas, ápice acuminado e viloso, 1-1,5×0,5-0,6 mm; prolongamento do receptáculo assimétrico, comprimido, pubescente, côncavo-convexo, 1-1,4×1,2-1,4 mm; receptáculo cupuliforme, externamente pubérulo e internamente glabro, 1-1,3×1-1,3 mm; lobos do cálice 5,

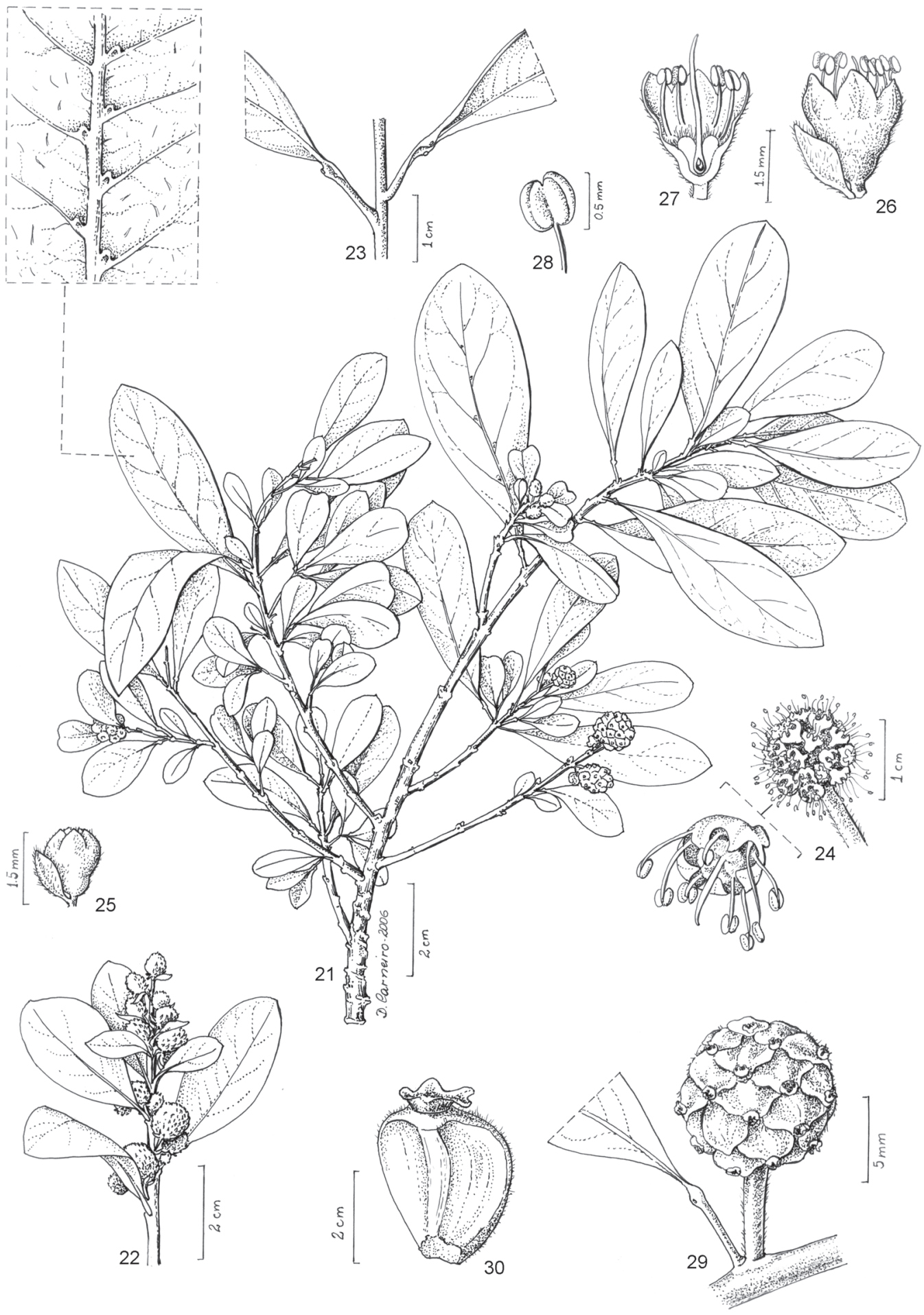

Figuras 21-30. Conocarpus erectus L. 21. Ramo com flor. 22. Ramo terminal. 23. Pecíolo. 24. Inflorescência. 25. Botão floral. 26. Flor inteira. 27. Secção longitudinal na flor. 28. Antera. 29. Infrutescência. 30. Fruto (M. Borgo, B.L. Reinert \& M.R. Bornschein 528). 
triangulares, glabros, 0,3-0,5 mm; disco nectarífero curto, espessado, lobado, pubescente, $0,4 \mathrm{~mm}$; apétalas; estames 5 , filetes filiformes, $0,8-1,2 \mathrm{~mm}$, anteras orbiculares, 0,2-0,4 $\mathrm{mm}$ compr.; ovário cilíndrico, estilete suavemente arqueado, 0,5-0,8 mm; estigma truncado. Frutos organizados em capítulos globosos, suberoso-coriáceos, axilares ou terminais, subsésseis, 3-3,6×3,8-4 mm, imbricados, reflexos, escamiformes, apiculados, recurvados, obovóides, alas laterais 2, rígidas, glabras, inconspícuas; pedicelo frutífero nulo.

Os indivíduos de $C$. erectus são facilmente reconhecidos pela inflorescência em capítulos globosos. Desenvolve-se em ambientes de estuários sobre forte influência da maré, ocorre com freqüência em manguezais, sendo menos comum nas restingas. Apresenta como limite austral a região da baía de Paranaguá, Paraná, sendo a primeira citação da espécie para o sul do Brasil. Pode-se dizer que o táxon não se encontra ameaçado de extinção, pois o local de ocorrência da espécie faz parte da Área de Preservação Ambiental da Baía de Paranaguá. Floresce e frutifica no mês de agosto.

Distribuição geográfica: litoral meridional da Flórida, Bahamas, Índias Ocidentais, México, América Central e Ilhas Galápagos. Na América do Sul se desenvolve do Equador até o Brasil. Também é nativo das áreas litorâneas da África Ocidental (Marquete \& Valente 1997). No Brasil foi registrada nas áreas litorâneas do Pará até o litoral norte do Paraná.

Material examinado: BRASIL. Paraná: Paranaguá, Rio dos Almeidas, 28/VIII/1999, M. Borgo, B.L. Reinert \& M.R. Bornschein 528 (UPCB).

Material adicional: BRASIL. São Paulo: Cananéia, Ilha do Cardoso, 15/IV/2005, R.S. Bianchini 1580 (SP); Ilha do Cardoso, Rio Pereque, 10/VI/1995, Y. Schaeffer s.n. (SPF). Bahia: Salvador, 2/VIII/1951, I.D.E. Menezes 23 (MBM); Prado, 1/XII/1997, S. Guedes 1069 (MBM); 21/IX/1987, H. Batista 1432 (MBM). Pará: Belém, Salinópolis, 7/X/1957, E. Pereira 3245 (HBR).

5. Buchenavia kleinii Exell, Ann. Magaz. Nat. Hist. Ser. Bot. 12(6): 400.1953.

Fig. 31-36

Árvores 10-30 m alt. Ramos superiores glabros, quando jovens densamente ferrugíneos e pubescentes. Folhas alternas, coriáceas, cartáceas, congestas, obovadas, oblonga-lanceoladas a oblongas, base cuneada, ápice arredondado, menos frequiente emarginado, suavemente acuminado, quando jovens amplamente pilosas, quando adultas pubescentes ou glabras na região adaxial, exceto na nervura principal, com indumento tomentoso, esparso na face abaxial, pubescente na nervura principal, 40-110×24-55 mm, domácias muitas vezes presentes; pecíolos eretos, pubérulos, 4-20 mm compr.; Inflorescências espigas axilares, subcapitadas; raque $10-20 \mathrm{~mm}$, rufopubescente. Flores sésseis 2,8-5,7 mm; brácteas ovaladas, oblongo lanceoladas, espessas, pubérulas, velutinorufescentes, 1,3-2,3 mm compr.; prolongamento do receptáculo rufo-pubescente, 1,4-3,4 mm; receptáculo pubescente, cupuliforme, 1,4-2,3 $\mathrm{mm}$, lobos do cálice 5, inconspícuos, 0,3-0,6 mm compr.; apétalas; estames 10, filetes, delgados e curtos, dispostos em duas séries, 0,9-1,5 mm; anteras adnatas aos filetes, elipsóides, $0,3 \times 0,5 \mathrm{~mm}$; disco nectarífero viloso-rufescente, consistente, 0,6-0,9 mm; ovário cilíndrico, estilete espesso, 1,4-2 mm; estigma truncado. Fruto elíptico ou obovóide, drupáceo, pubérulo, apiculado ou arredondado no ápice, 25-36x 14-21 mm, rufo-tomentosos, pedicelo frutífero glabro ou pubérulo, 11-16 mm.

Buchenavia kleinii caracteriza-se pelos frutos elíptico ou obovóide, drupáceos, e tricomas rufo-tomentosos, essa característica fazem-na diferir de B. hoehneana N. Mattos, espécie próxima, que ocorre nos estados de São Paulo e Rio de Janeiro. Ocupa áreas de floresta ombrófila densa de encosta entre 50 e $800 \mathrm{~m}$ de altitude na vertente oriental da Serra do Mar. Menos freqüência em áreas de Floresta Ombrófila Densa de planície aluvial, interioranas, dos Vales do Ribeira e Itajaí. Segundo a IUCN (2003) o táxon encontrase em risco de extinção. Uma oportunidade de conservação da espécie é o fato dela ocorrer no Parque Nacional Saint Hilaire-Lange, região serrana do litoral do Paraná. Floresce de dezembro a janeiro e frutifica de janeiro a abril.

Distribuição geográfica: Brasil: Rio de Janeiro, São Paulo, Paraná, Santa Catarina e Rio Grande do Sul (Marquete \& Valente 1997).

Material examinado: BRASIL. Paraná: Adrianópolis, Rio Pardo, 1/IX/1976, G. Hatschbach 37890 (MBM); Antonina, Cacatu, 29/I/1968, G. Hatschbach 18488 (HBR), 17/III/2000; Guaraqueçaba, Serrinha, G. Hatschbach 18271, 11/I/1968 (MBM, UPCB, HBR, SPF); Morretes, 7/XI/1968, G. Hatschbach 20232 (MBM; UPCB). Santa Catarina: Florianópolis, Morro do Rio Vermelho, R.M. Klein \& Bresolin 7678 (HBR); Itajaí, Cunhas, 10/III/1955, R.M. Klein 1182 (HBR, PACA, ICN); Blumenau, Morro Spitzkopf, 11/III/1960, R.M. Klein 2424 (HBR); Governador Celso Ramos, Jordão, R.M. Klein 10054, 22/II/1972 (MBM, ICN, HBR); Itapoá, Reserva Velha, $R$. Negrele \& C. Londero A-829, 3/III/1993 (MBM, UPCB); Lauro Müller, Vargem Grande, R. Reitz \& R.M. Klein 8494 (HBR); Rio do Sul, Alto Matador, 30/XII/1958, R. Reitz 6126 (SP, UPCB, PACA; HPEL); Sombrio, Guapuruvu, Vista Alegre, 12/XII/1959, R. Reitz \& R.M. Klein 9409 (HBR). Rio Grande do Sul: Dom Pedro de Alcântara, 17/IV/1999, M.G. Rossoni s.n. (ICN).

6. Terminalia australis Camb., Fl. Bras. Merid. 2: 240, t. 128. 1829.

Fig. 52-57

Árvores 2-10 m alt. Ramos terminais glabros, alongados, flexíveis. Folhas alternas congestas no ápice dos ramos, 1,5-8 cm, estreitamente elípticas ou oblongo-elípticas, coriáceas, tomentosas nas jovens e quando adultas pubérulas, margem pubescentes; domácias marsupiformes na nervura principal com as secundárias, base cuneada, ápice agudo, muitas vezes com apículo, ou arredondada; pecíolo breve e pubescente, 0,3-0,6 cm. Inflorescências espigas 
axilares, menos freqüentes terminais, raque tomentosa 3-4,8 mm. Flores amarelo-esverdeadas, 2-4,5×4-4,7 mm; brácteas triangulares, $1-2 \times 1 \mathrm{~mm}$, lanosas; prolongamento do receptáculo fusiforme, 1,4-2×0,4-0,6 mm, velutino; receptáculo campanulado $2-2,5 \times 3-3,2 \mathrm{~mm}$, tomentoso, lobos do cálice 5, triangulares, 1-1,3×0,5-0,6 mm, reflexos; disco nectarífero volumoso na extremidade, $2,5 \mathrm{~mm}$, viloso; apétalas; estames 10, 4-5 mm, filetes filiformes, anteras orbiculares, versáteis aos filetes, $0,7 \times 0,5 \mathrm{~mm}$.; ovário cilíndrico, estilete subulado, 3-5,5 $\mathrm{mm}$, velutino na base, estigmas truncados. Fruto betulídio, lateralmente comprimido, 1,2-2,6×1-1,8 cm, alas 2 com 2-6 mm compr., todas menores que a largura do corpo, coriáceas, elipsóides, pubescentes ou glabras; pedicelo frutífero delgado, pubescente, 1,9-4,7 cm.

Terminalia australis diferencia-se dos demais táxons pelos frutos estreitos, elipsóides, lateralmente comprimidos e alas menores que a largura do corpo. Desenvolve-se com
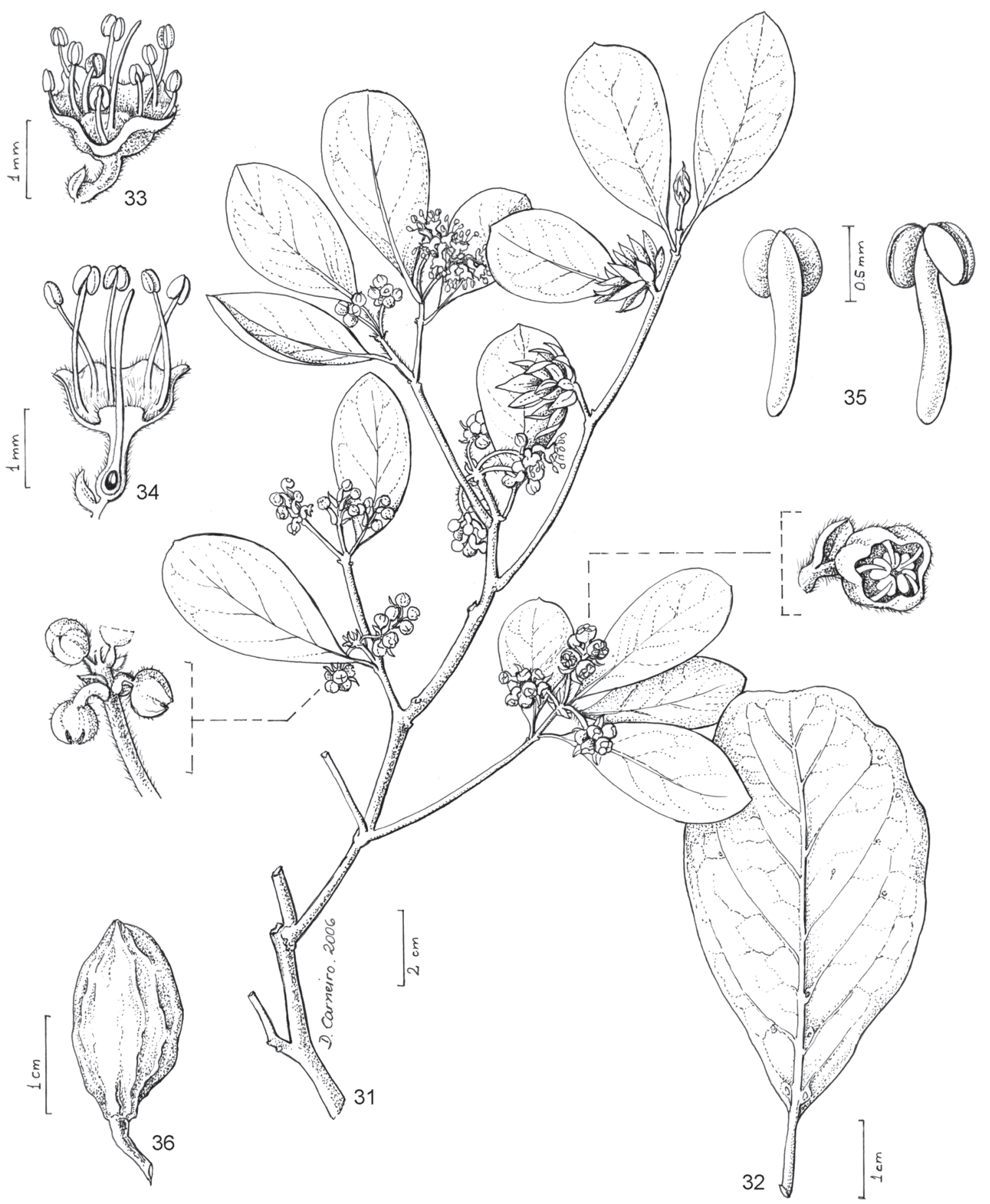

Figuras 31-36. Buchenavia kleinii Exell. 31. Ramo com flor. 32. Folha. 33. Flor inteira. 34. Secção longitudinal na flor. 35. Estames. 36. Fruto (G. Hatschbach $18271)$. 
freqüência na floresta estacional semidecídual, nos terrenos aluviais, da região oeste do Paraná e Santa Catarina. No Rio Grande do Sul forma agrupamentos disformes ao longo dos principais rios planálticos do estado.

A espécie está protegida da extinção por ocorrer no Parque Nacional do Iguaçu e Parque Estadual do Rio Guarani, ambos no estado do Paraná. Floresce em outubro e novembro. Frutifica de dezembro a março.

Distribuição geográfica. Argentina e Uruguai. No Brasil ocorre em todos os estados da região sul (Exell \& Reitz 1967).

Material examinado: BRASIL. Paraná: Dois Vizinhos, 9/XII/1968, G. Hatschbach 20575 (MBM, SP; HBR); Enéas Marques, 11/X/1974, G. Hatschbach 35171 (MBM); Foz do Iguaçu, 2/XI/1998, Acildo 146 (MBM); Nova Prata do Iguaçu, 15/X/1997, J.M. Silva 2213 (MBM). Santa Catarina: Anita Garibaldi, 22/XII/1962, R. Reitz \& R.M. Klein 14448 (MBM, HBR); Concordia, 24/X/1964, L.B. Smith \& R. Reitz 12935 (HBR, MBM); Itapiranga, Rio Uruguai, 17/X/1964, L.B. Smith \& R. Reitz 12644 (HBR). Rio Grande do Sul: Caçapava do Sul, 9/XI/1996, J.A. Jarenkow 3253 (MBM; HPEL); Camaquã, 31/X/1989, J.A. Jarenkow \& J.L. Waechter 1370 (MBM; HPEL), Caxias do Sul, Forromeco, 03/I/1949, A. Sehnem s.n. (PACA); Gramado, Gravataí, 11/XI/1949, B. Rambo s.n. (PACA, HAS); Missões, Cerro Largo, 20/XI/1952, B. Rambo s.n. (PACA); Passo Fundo, 20/I/1957, O.R. Camargo 2206 (PACA); Pelotas, 2/XII/1957, J.C. Sacco 776 (PACA; HPEL); Porto Alegre, Ponta Grossa, 14/XI/1948, B. Rambo 38008 (PACA; HBR, HAS); Santa Cruz do Sul, Pardinho, 1/XI/1987, J.A. Jarenkow 790 (PACA, MBM), São Gabriel, Fazenda Santa Cecília, 01/I/1944, B. Rambo s.n. (PACA); São Jerônimo, Mata do Ingá, 18/X/1982, M. Neves 132 (SP); Vacaria, rio Santa Rita, 29/XI/1980, A. Krapovickas \& R. Vanni 37040 (ETESN).

7. Terminalia glabrescens Mart., Fl. Bras. 20(2): 124. 1837 et 24(2): 231841.

Fig. 37-44

Árvores 8-12 m alt. Ramos terminais pubescentes. Folhas alternas, obovadas ou obovado-lanceoladas, base cuneada, ápice agudo, arredondado ou levemente emarginado, biglandulosas na base, $6,2-11 \times 2,8-4,7 \mathrm{~cm}$, adultas coriáceas, jovens membranáceas, pubescentes; domácias marsupiformes nas axilas da nervura primária com a secundária; pecíolos pubescentes, 5-8 $\mathrm{mm}$. Inflorescências espigas axilares, glomeradas no ápice; raque rufo-pubescente, $7-10 \mathrm{~cm}$. Flores brancas ou esverdeadas, 4-5 mm; prolongamento do receptáculo viloso-tomentoso, rufescente, 1,8-2,5×2,3-1,5 mm; receptáculo campanulado, viloso-rufescente na parte externo e interna, 1,2-1,8× 2-2,5 mm.; lobos do cálice 5, triangulares, 0,7-0,9×0,8-1,2 mm; disco nectarífero curto, carnoso, 5-lobado, densamente viloso, 0,3-0,4 mm; apétalas; estames 10, 3-3,8 mm, filetes filiformes, alongados, anteras orbiculares, versáteis aos filetes, 0,4-0,6 mm; ovário cilíndrico, estilete alongado, 3,7-3,8 mm, estigma obtuso. Fruto betulídio, 0,4-0,8×1,1-2 cm, com 5 alas desiguais, 2 alas maiores que a largura do corpo e 3 menores, rufo-pubescentes quando jovens e pubérulas quando adultas, escariosas; pedicelo frutífero curto, rufopubescente, $2-3 \mathrm{~mm}$.

Terminalia glabrescens possui como característica mais evidente o fruto com cinco alas desiguais. O norte do Paraná é o limite austral de ocorrência e se desenvolve nas áreas de floresta estacional semidecídua e nas formações de cerrado.

A espécie no sul do Brasil encontra-se ameaçada de extinção. O principal fator responsável é a substituição dos fragmentos de cerrado por monoculturas.

Distribuição geográfica: Paraguai. Brasil: Maranhão, Ceará, Bahia, Mato Grosso, Mato Grosso do Sul, Distrito Federal, Goiás, Minas Gerais, Espírito Santo, Rio de Janeiro, São Paulo e Paraná (Marquete 1995).

Material examinado: BRASIL. Paraná: Cianorte, 26/VIII/1967, G. Hatschbach 16984 (MBM, HBR); 26/VIII/1967, G. Hatschbach 16986 (MBM; HBR); 17/IX/1986, R. Carvalho 275 (MBM).

Material adicional: BRASIL. São Paulo: Paulo Faria, 2/X/1994, R.R. Rodrigues \& S. Gandolfi 314 (SPF); Dracena, 7/IX/1995, L.C. Bernacci et al. 2046 (SPF); Pereira Barreto, Fazenda Esmeralda, 2/VIII/1995, N.R.P. Noronha 1186 (SPF).

\section{Terminalia argentea Mart., Gen. Sp. Pl. 1: 43. 1824.} Fig. 45-51

Árvores $8 \mathrm{~m}$ alt. Ramos sedosos, superiores glabrescentes. Folhas alternas, elípticas, agudas, menos freqüente acuminado no ápice, cuneadas na base, argênteotomentosas, principalmente quando jovens, pubérulas em ambas as faces; domácias marsupiformes, nas nervuras principais com as secundárias; pecíolos $1-2 \mathrm{~cm}$, às vezes biglandulosos na base, pubérulos. Inflorescências espigas capituliformes, axilares, alongadas, aglomeradas no ápice dos ramos, raque argênteo-tomentosa, 1,2-4,3 cm. Flores creme-esverdeadas a amarelas, 3,5-5 ×2,8-3,2 mm; brácteas lanceoladas, pubescentes, $1,5 \times 0,6 \mathrm{~mm}$; prolongamento do receptáculo fusiforme, sedoso, 1,5-2×0,6-0,8 mm; receptáculo campanulado $2 \times 2,5 \mathrm{~mm}$, externamente pubérulo ou sedoso, internamente viloso, lobos do cálice 5 , ovalados, reflexos, 0,5-1,2×0,5-0,6 mm.; disco nectarífero breve, lobado, 0,4 mm; apétalas; estames $10,3 \mathrm{~mm}$ compr., filetes filiformes, anteras orbiculares, versáteis aos filetes, $0,5 \times 0,5 \mathrm{~mm}$; ovário cilíndrico, estilete subulado, piloso na base, 3-3,4 mm, estigma truncado. Fruto betulídio, $2 \times 3-5 \mathrm{~cm}$, emarginado no ápice e cordado na base, alas 2 , elípticas, transversalmente arredondadas, maiores que a largura do corpo, coriáceas, pubescentes; pedicelo frutífero pubescente, $1,2-2 \mathrm{~cm}$.

A espécie, quando perde o indumento, assemelha-se a Terminalia phaeocarpa Eichler, da qual se distingue pelos frutos com alas arredondadas. $\mathrm{O}$ ambiente típico de ocorrência são as formações de cerrado e as zonas de ecótono com as florestas estacionais. O estado do Paraná é o limite austral de sua ocorrência. Provavelmente encontra-se extinta na região sul. Existe apenas um registro, em 1959, na região do rio do Funil no município de Sengés. 
Essa área compreende uma pequena extensão da vegetação de cerrado do estado de São Paulo. O único exemplar da região sul examinado estava florido e frutificado no mês de setembro.

Distribuição geográfica: Goiás, Bahia, Ceará, Distrito Federal, Mato Grosso do Sul, Mato Grosso, Minas Gerais, Paraná, São Paulo e Tocantins (Marquete \& Valente 1997a).
Material examinado: BRASIL. Paraná: Sengés, Fazenda Morungava, 9/IX/1959, G. Hatschbach 6271 (MBM; HBR).

Material adicional: BRASIL. São Paulo: Mogi-Guaçú, 9/VII/1988, G. Eiten 2213 (SP, SPF); 22/XII/1965, J. Mattos \& N. Mattos 13132 (SPF); Iguaçaba, 12/XI/1994, W. Marcondes-Ferreira et al. 1046 (SPF); Ilha Solteira, 10/IX/1992, F. Barros 2496 (SPF); São João da Boa Vista,

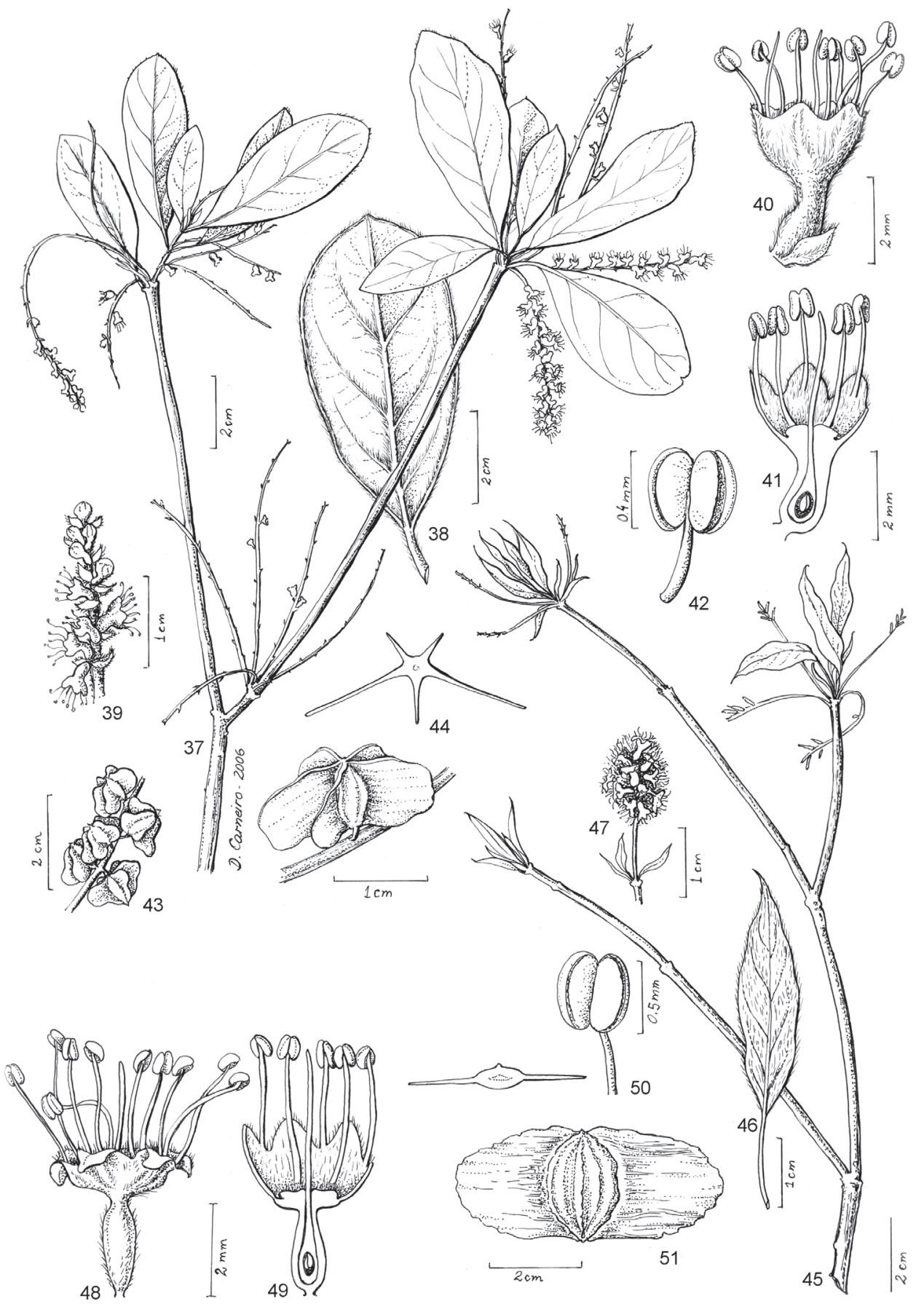

Figuras 37-51. Terminalia glabrescens Mart. 37. Ramo com flor. 38. Folha. 39. Inflorescência. 40. Flor. 41. Secção longitudinal na flor. 42. Antera. 43. Frutos. 44. Detalhe do fruto. Terminalia argentea Mart. 45. Ramo com flor. 46. Folha. 47. Inflorescência. 48. Flor. 49. Secção longitudinal na flor. 50. Antera. 51. Fruto (37-44. G. Hatschbach 16984; 45-51. G. Hatschbach 6271). 
17/VII/1991, H. Lorenzi s.n. (SPF). Minas Gerais: Contagem, 9/VII/1945, L.O. Willians \& A. Assis 7426 (SPF); Paracatu, 4/III/1989, R.C. Dias s.n. (SP).

9. Terminalia triflora (Griseb.) Lillo, Contr. Conoc. Arb. Arg. 20. 1910. Chuncoa triflora Griseb. in Abh. Königl. Ges. Wiss. Göttingen 24: 132. 1879.

Fig. 58-67

Árvores 4-20 m alt. Ramos terminais pubescentes. Folhas alternas, elípticas, lanceoladas a oblongas, 2-10x 1-4 cm, rufo-pubescentes, principalmente quando jovens, adultas com a face adaxial subglabra, ápice agudo, muitas vezes com apículos vilosos, raramente arredondado, base atenuada; pecíolos rufescentes, 0,5-1,4 cm compr., quando jovens densamente pubescentes, quando adultas pubescentes ou glabras, margem inteira e seríceas; domácias marsupiformes na axila da nervura primária com as secundárias, nervuras rufescentes, 0,5-1,4 cm compr. Inflorescências de espigas axilares, freqüentemente 3 a 6 flores no ápice; raque pubescente, $10-20 \mathrm{~mm}$ compr. Flores creme-esverdeadas a amareladas, 3,5-5,5 mm compr., subsésseis; prolongamento do receptáculo fusiforme, estreito, 1,5-2,3×0,3-0,5 mm, sedoso; receptáculo campanulado, $2 \times 3-3,8 \mathrm{~mm}$, pubescentes exteriormente, interiormente tomentoso; lobos do cálice reflexos, triangulares $0,7-1,2 \times 0,5-0,7 \mathrm{~mm}$; disco nectarífero circular, na base do estilete, espessado na extremidade, viloso, 0,3-0,4 mm compr.; apétalas; estames 10,3-3,8 mm compr., filetes filiformes, anteras orbiculares, versáteis aos filetes, 0,4×0,5 mm.; ovário cilíndrico, estilete subulado, pubescente na base, 4-5 mm compr., estigma delgado. Frutos betulídios com 2 alas laterais, $0,8-2,5 \times 1,6-4,5 \mathrm{~cm}$, maiores que o corpo do fruto, transversalmente triangulares, subtriangulares, oblongas, arredondadas, pubérulos ou glabros, coriáceos; pedicelo frutífero pubérulo, $1,5-4 \mathrm{~cm}$.

Planta facilmente reconhecida por apresentar casca fendida, folhas deciduais e frutos com duas alas transversalmente triangulares, subtriangulares ou arredondadas.

Terminalia trifora apresenta complexa variação morfológica nas folhas e nos frutos, principalmente nas populações da região de Rio do Sul e Tubarão em Santa Catarina. No estado do Paraná a espécie apresenta alas mais estreitas e triangulares, folhas menores, semelhantes à espécie da Bolívia, Paraguai e São Paulo. A variação foliar encontrada, possivelmente pode ser uma adaptação à variação de hábitats. Em Santa Catarina ocorre em áreas de floresta ombrófila densa, nos demais estados em áreas de floresta estacional semidecídual. Apresenta vasta e expressiva dispersão, estendendo-se de forma irregular e descontínua até o rio Paraguai e Paraná. A espécie apresenta poucos registros recentes, possivelmente encontra-se ameaçada de extinção devido ao desmatamento. A Floração ocorre nos meses de setembro e outubro e a frutificação de novembro a fevereiro.

Distribuição geográfica. Bolívia, Paraguai e Argentina. Brasil: Mato Grosso do Sul, Minas Gerais, São Paulo, Paraná e Santa Catarina.

Material examinado: BRASIL. Paraná: Foz do Iguaçu, Parque Nacional do Iguaçu, 9/XI/2000, A. Cervi et al. 8108 (MBM, UPCB); Rio Ocoí, 18/IV/1981, G. Hatschbach 44008 (MBM); 18/VIII/1999, G. Hatschbach \& J.M. Silva 69273 (MBM); Joaquim Távora, 30/XI/1976, G. Hatschbach 39279 (SPF, MBM); Leópolis, 29/VIII/1996, F. Chagas \& Silva s.n. (HPEL; FUEL); Paranavaí, 18/VIII/1999, G. Hatschbach \& J.M. Silva 69273 (MBM); Santa Fé, Rio Bandeirantes, 1/IX/1989, J.M. Silva \& G. Hatschbach 640 (MBM); São Miguel do Iguaçu, Rio Ocoí, 18/IX/1981, E. Buttura 679 (MBM); Sapopema, Fazenda Bom Sucesso, 17/XII/1990, M.C. Dias s.n. (MBM); Terra Roxa, Rio Acú, 31/I/1986, U. Pastore \& R.M. Klein 177 (MBM); Tibagi, Fazenda Batavo, 30/IV/1990, F. Chagas \& Silva s.n. (MBM). Santa Catarina: Florianópolis, 14/X/1969, R.M. Klein \& Bresolin 8349 (MBM, HBR; HPEL); Morro da Quebrada, 16/XII/1969, R.M. Klein \& Bresolin 8428 (MBM); 1/I/1952, R.M. Klein \& Bresolin s.n. (SMDB); 16/XII/1969, R.M. Klein \& Bresolin 8495 (MBM; HBR); Canavieiras, 19/XI/1969, R.M. Klein s.n. (MBM); 19/XI/1969, R.M. Klein 8467 (HBR); Rio do Sul, 16/XIII/1963, R. Reitz \& R.M. Klein 16138 (MBM, HBR); Serra do Matador, 21/II/1962, R. Reitz \& R.M. Klein 12194 (HBR; SP); 11/IX/1958, R. Reitz \& R.M. Klein 7076 (HBR; SP); 11/IX/1963, R. Reitz \& R.M. Klein 16138 (HBR; MBM; PACA; SP).

Espécies duvidosas:

Terminalia uleana Alwan Al-Mayah, A.-R. A. \& C.A. Stace in Ann. Missouri Bot. Gard. 76(4): 1125-1128. 1989.

O táxon é representado apenas pela coleção-tipo, proveniente do município de Tubarão, Santa Catarina (a coleção-tipo não está representada por material em flor). Alwan \& Stace (1989) consideram esse táxon diferente de Terminalia triflora, apenas pela curvatura basioscópica na região do fruto, entre as alas, no ponto de inserção do pedúnculo. Assim, Terminalia uleana foi tratada como espécie duvidosa.

Terminalia reitzii Exell in Sellowia 16: 191-192. 1964.

Exell (1964) diferencia Terminalia reitzii de Terminalia triflora por apresentar folhas maiores, $10 \times 4 \mathrm{~cm}$, frutos desenvolvidos, $2,8-4,5 \times 2-2,5 \mathrm{~cm}$, e com alas oblongas. Tais características são inconsistentes para o estabelecimento de uma espécie. Por isso, T. reitzii está sendo tratada como espécie duvidosa. 

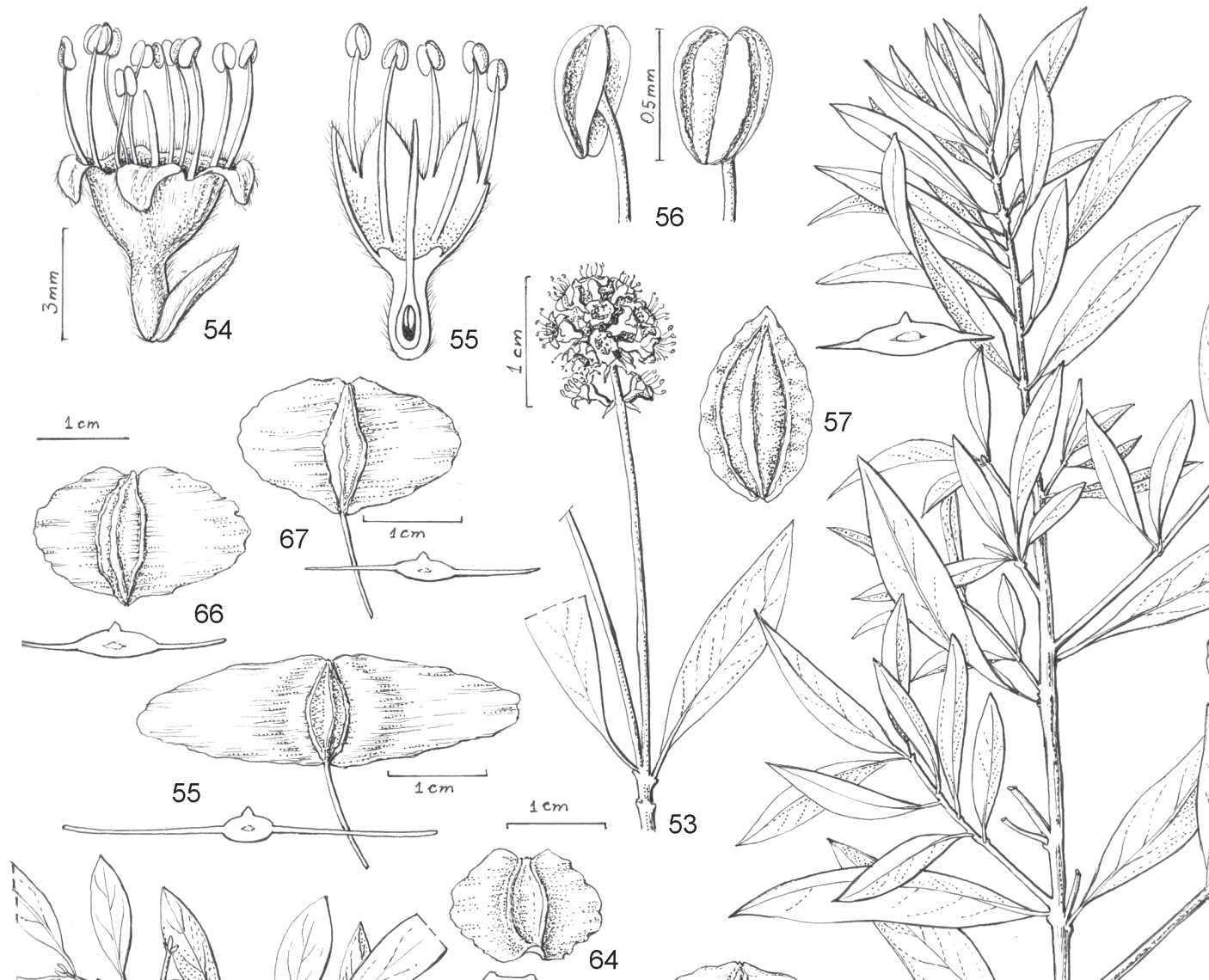
${ }_{153}$



57
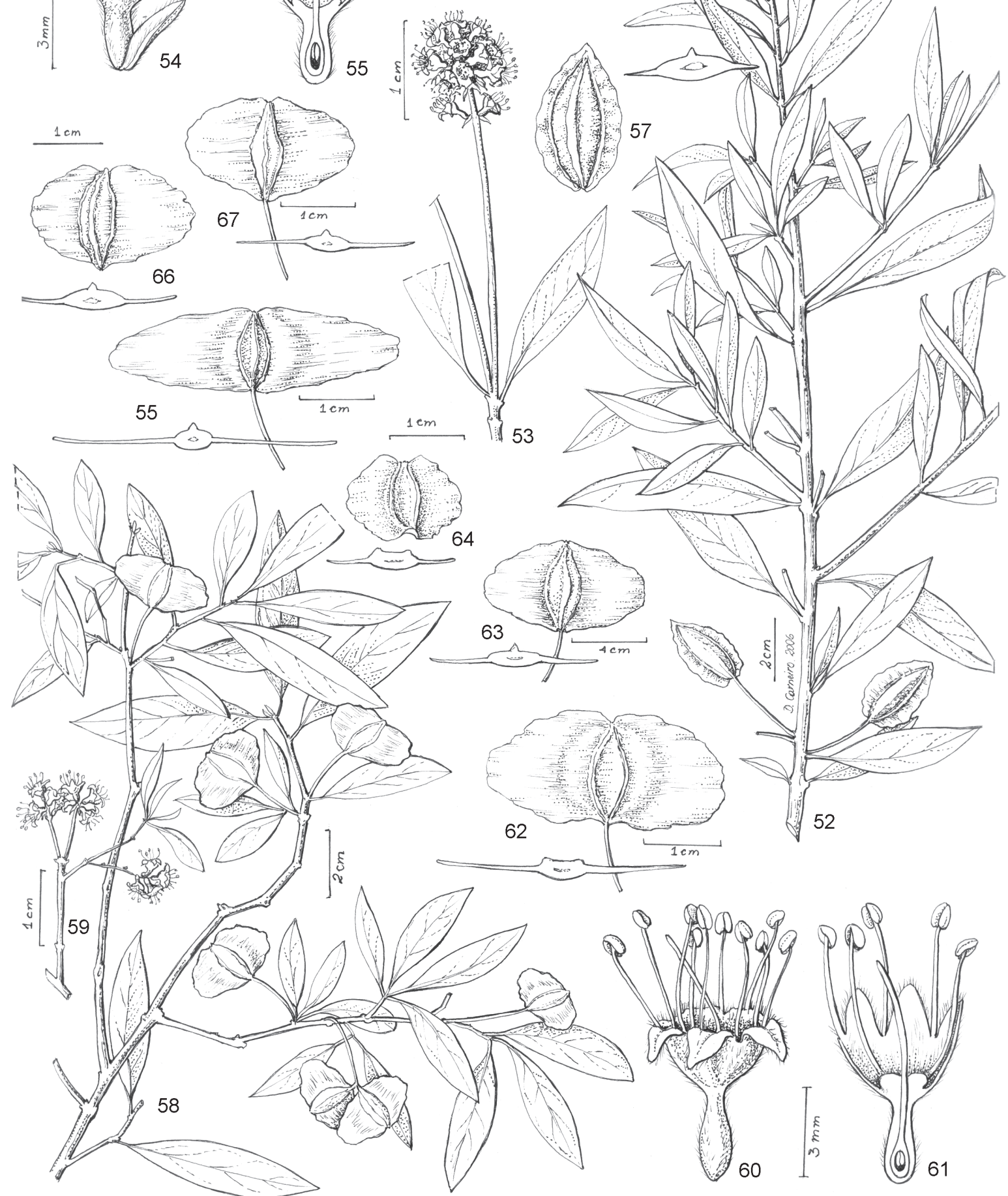

Figuras 52-67. Terminalia australis Cambess. 52. Ramo com fruto. 53 Inflorescência. 54. Flor inteira. 55. Secção longitudinal na flor. 56. Antera. 57. Fruto. Terminalia triflora (Griseb.) Lillo., 58. Ramo com fruto. 59. Inflorescência, 60. Flor. 61 Secção longitudinal na flor. 62. Fruto. 63. Fruto. 64. Fruto. 65. Fruto. 66-67. Fruto (52-57. G. Hatschbach 20575; 58. R. Reitz \& R.M. Klein 7076; 59-61. R. Reitz \& R.M. Klein 16138; 62. A. Cervi et al. 8108; 63. N.F. Chagas \& Silva s.n.; 64. M.C. Dias s.n.; 65. G. Hatschbach 44008; 66-67. E. Buttura 679). 


\section{Agradecimentos}

À CAPES, pela concessão da bolsa de Mestrado; aos curadores dos herbários UPCB, ICN, PACA e MBM, pela eficiente logística e auxílio; aos botânicos Cleto Kaveski, Elton Assis, Pedro Swartsburg, Paulo Labiak, Clive Stace, Gerdt Güenther Hatschbach e Willian Rodrigues, pelas calorosas discussões e comentários, e em especial à Faculdade Jaguariaíva e à Dra. Nilda Marquete, pelo auxílio e envio das publicações.

\section{Referências bibliográficas}

Brown, R. 1810. Prodromus florae Novae Hollandiae. Johnson, London, 1: 260-266.

Brummitt, R.K. \& Powell, C.E. 1992. Authors of plant names. Kew, Royal Botanic Gardens.

Eichler, A.W. 1867. Combretaceae. In: C.F.P. Martius. Flora Brasiliensis. Monachii, Oldenburg, 14: 77-128.

Engler, A. \& Diels, L. 1899. Combretaceae. In: A. Engler. Monographie en Afrikanischer Pflanzien-Familien und Gattur IV. Combretaceae. Leipzig.

Exell A.W. 1931. The genera of Combretaceae. Journal of Botany 69: 113-128.

Exell, A.W. \& Reitz, R. 1967. Combretáceas. Pp. 1-26. In: R. Reitz. Itajaí. Flora Ilustrada Catarinense, Itajaí.

Exell, A.W. \& Stace, C.A. 1966. Revision of the Combretaceae. Boletim da Sociedade Broteriana, Coimbra, 40: 5-25.

Holmgren, P.K.; Holmgren, N.H. \& Barnet, L.C. 1990. Index Herbariorum, Part 1: The herbaria of the world. $8^{\text {th }}$ ed. New York, New York Botanical Garden.

IUCN. 2003. IUCN Red List of threatned species. http// www.redlist.org.

Lawrence, G.H.M. 1951. Taxonomia das plantas vasculares 2. Lisboa, Fundação Calouste Gulbenkian.
Loiola, M.I.B. \& Sales, M.F. 1996. Estudos taxonômicos do gênero Combretum Loefl. (Combretaceae R. Br.) em Pernambuco Brasil. Arquivos do Jardim Botânico do Rio de Janeiro 34: 173-188.

Marquete, N.F.S. 1984. Combretaceae do Estado do Rio de Janeiro. Subtribo Terminaliinae, Rodriguésia 36: 81-104.

Marquete, N.F.S. 1995. Combretum Loefling do Brasil-Sudeste (Combretaceae). Arquivos do Jardim Botânico do Rio de Janeiro 33: 55-107.

Marquete, N.F.S. \& Valente, M.C. 1996. Combretaceae In: Coleção Rizzo, Flora dos Estados de Goiás e Tocantins, Brasília, 19: 1-59.

Marquete, N.F.S. \& Valente, M.C. 1997. Combretaceae In: M.C.M Marques \& H.F. Martins, Flora do Estado do Rio de Janeiro. Albertoa 4: 13-51.

Marquete, N.F.S. \& Valente, M.C. 2003. Combretaceae In: Cavalcante, T.B. \& Ramos, A.E. Flora do Distrito Federal, Brasil. Embrapa: Recursos Genéticos e Biotecnologicos 3: $153-170$

Marquete, N.F.S; Teixeira, J. \& Valente, M.C. 2003. Terminalia L. (Combretaceae) na região Sudeste do Brasil. Rio de Janeiro, Bradea 9: 99-123.

Radford, A.E.; Dickinson, W.C.; Massey, J.R. \& Bell, C.R. 1974. Vascular Plants Systematics. New York, Harper \& Row.

Stace, C.A. 1965. The significance of the leaf epidermis in the taxonomy of the Combretaceae I. General rewiew of the tribal, generic and species characters. Botanical Journal of the Linnean Society 27: 1-28.

Tomlinson, P.B. 1986. The botany of mangroves. Cambridge, Cambridge University Press.

Veloso, H.P. 1992. Sistema Fitogeográfico. In: V.R. dos Anjos (ed.). Manual Técnico da Vegetação Brasileira. Rio de Janeiro, IBGE. 